\author{
Yong Luo \\ China Agricultural University, Beijing, P. R. China \\ University of California-Davis, Kearney Agricultural Center, Parlier, CA, U.S.A.
}

\title{
Long-Distance Spread and Interregional Epidemics of Wheat Stripe Rust in China
}

China, one of the largest wheat producing and consuming countries, produces over 90 million metric tons of wheat annually, or approximately $17 \%$ of the world's wheat. According to the China Statistical Yearbook 2004, the total area under winter and spring wheat was 21.6 million hectares. As a food crop, wheat ranks second to rice in China. Wheat is grown at different geographical regions with various elevation and climate (Fig. 1). Winter wheat is mainly grown between 22 and $42^{\circ} \mathrm{N}$ latitude and between 75 and $97^{\circ} \mathrm{E}$ longitude, and spring wheat is mainly grown north of $42^{\circ} \mathrm{N}$ and in high altitude mountain regions in the western and southern parts of China, but the hectarage is relatively limited. Wheat is produced in 34 provinces of China (Fig. 2). The eight major winter wheat growing provinces are located in north-central (Hebei and Henan provinces), northwestern (Gansu and Shaanxi provinces), east-central (Shandong Province), southeastern (Jiangsu and Anhui provinces), and southwestern (Sichuan Province) China. Stripe rust, caused by Puccinia striiformis Westend. f. sp. tritici Eriks. \& Henn., has been the most destructive wheat disease (Fig. 3). The epidemics of 1950, 1964, 1990, and 2002 caused yield losses up to 6.0, 3.0, 1.8, and 1.3 million metric tons, respectively $(7,13)$.

Wheat stripe rust is a worldwide destructive disease causing severe yield losses, especially in North America, Europe, and Asia $(3,8,15)$. It also was introduced into Australia in 1979 (9) and into New Zealand in 1980 (12). In China, stripe rust exhibits a unique system which involves diverse and complicated cropping systems, geographic and climatic conditions, and pathogen life cycle features. Pandemics of the disease across various regions occasionally occur in China. The unique administrative system of this coun-

Corresponding author: Yong Luo E-mail: yluo@uckac.edu

DOI: 10.1094/PD-90-0980

(c) 2006 The American Phytopathological Society try made it feasible to conduct extensive across-regions cooperative research on long-distance disease spread. This report summarizes the China studies on longdistance disease spread and the complex regional classification of stripe rust epidemics.

\section{Features of Stripe Rust in China}

The biology of $P$. striiformis was studied intensively in the mid-1950s (7). No sexual phase of this pathogen has been found in China. Uredospores are the only spore type involved in disease development. Compared with the situation in North America, where the pathogen can survive on wild grass at high elevations in summer serving as initial inoculum in the fall (8), no evidence has been found of natural infection and reproduction of the pathogen on grasses in China, unless artificial inoculation is implemented (7). The pathogen requires susceptible living green wheat plants for survival and reproduction and appropriate climatic conditions for overwintering and oversummering (7). For overwintering, the lower temperature limit in January is -6 to $-7^{\circ} \mathrm{C}$ (monthly average of daily air temperatures recorded four times a day), or as low as $-10^{\circ} \mathrm{C}$ when wheat was under snow cover (7). On susceptible cultivars, the upper limit for oversummering is 20 to $22^{\circ} \mathrm{C}$ (Xun average highest temperature) (7). (Chinese Xuns are equivalent to 10-day periods: upper Xun, days 1 to 10 ; mid Xun, days 11 to 20; and lower Xun, days 21 to 28/31). These temperature limits are used to consider possible annual cycles of the pathogen in relevant areas (7) using local weather station data recorded four times a day (100, 700,1300 , and 1900) at 1.5-m height.

Compared with situations in North America and Europe, China shows a greater variation among wheat growing areas in physical features (geomorphological, pedological, and climatological) and in cultural characteristics (time of sowing and harvesting, rotation, and irrigation) and variety grown. In North America (8), the pathogen can survive in the Pacific Northwest and some other regions during the winter, and the early-sown wheat infected during the previous fall may provide the primary inoculum for disease epidemics in spring. The pathogen oversummering on wild grass can produce the spores that serve as the primary source of inoculum for fall-planted wheat (8). In Europe (15), the pathogen can overwinter in some wheat-growing countries, and spores from the infected leaves serve as the initial inoculum for spring epidemics. The pathogen can oversummer in pre- and postharvest self-sown plants serving as volunteers carrying stripe rust that infects fall-sown crops. The pathogen can also oversummer at high altitudes such as in the Alps. Some grasses might serve as secondary hosts, although the amount of inoculum on these hosts is very small. In China, there is considerable diversity in epidemiological conditions among the wheat-growing areas. Winter wheat does not grow during the frost period of the north-central Chinese winter, grows slowly during winter in the Yellow River Valley, and develops regularly during the winter months in the midstream area of the Yangzi River. Planting seasons range from September (northcentral) to December (southwest), whereas harvest seasons go from May (southeast) to August (northwest). The rust cannot overwinter in the northern zone, stretching from Shijiazhuang and Dezhou in Hebei Province to Jiexiu in Shanxi Province and Huangling in Shaanxi Province (2). South of this zone, the pathogen can overwinter if susceptible plants are available, and sometimes even multiplies slowly.

In most wheat growing areas, stripe rust cannot oversummer since summer temperatures usually exceed the limit value for pathogen survival. In China, the rust oversummers primarily in the mountainous regions of southern and eastern Gansu Province and northwestern Sichuan Province. The necessary conditions for oversummering of stripe rust in these regions are (i) an average maximum temperature $<22^{\circ} \mathrm{C}$ in the hottest Xun, and (ii) wheat crops of different maturity dates grown at different elevations, so that (iii) an overlap exists between the period of epidemics on 
late crops and the period with self-sown seedlings from early crops (7). After the summer (July and August), these volunteer wheat seedlings may produce huge amounts of spores (Fig. 4) that can be continuously blown eastward by the pre- vailing winds and cause infections on seedlings of newly sown crops in more easterly regions from late August to even early November. The mountain regions play a key role in the epidemiological geography of China.
A special crop, "year-round wheat", planted at the end of August and harvested about mid-September of the next year, provides the ideal conditions for local oversummering of stripe rust, since uredospores can move easily from the preced-

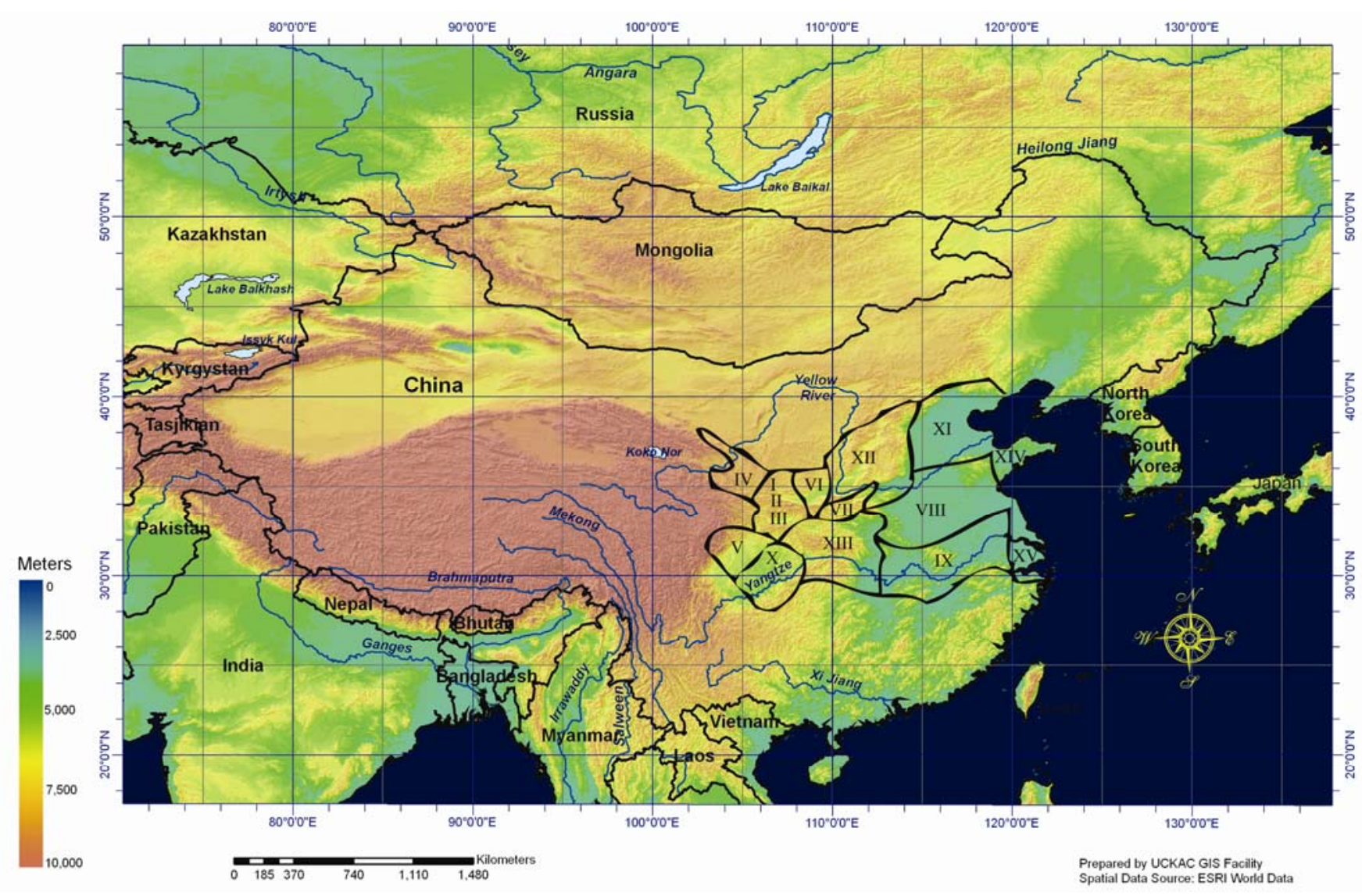

Fig. 1. Topographical map of China. The highlighted areas with black lines roughly indicate the 15 stripe rust epidemic regions (Table 1) based on geographic features related to stripe rust epidemics, cultural systems, characteristics of pathogen oversummering and overwintering, and frequency of disease epidemics. Long-distance disease spread and spore dispersal occur in spring from south to north and in fall from west to east among these epidemic regions.

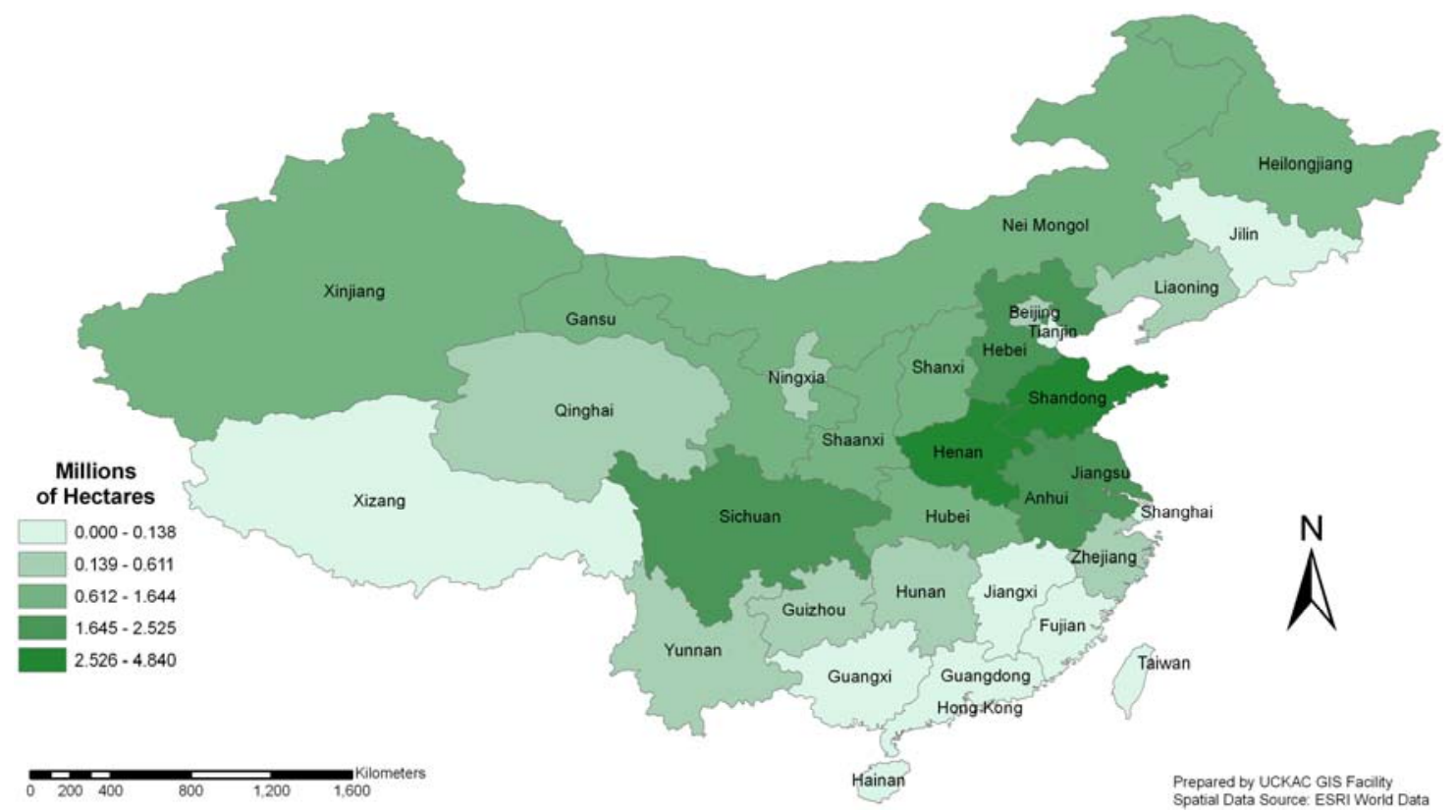

Fig. 2. Wheat is grown in 34 provinces of China with different hectarage. 
ing source crop to the succeeding target crop, owing to the overlap of these crops (23). This local annual cycle exists only in the northwestern area of Sichuan Province and possibly in the Yili Valley of Xinjiang Province. Since the hectarage under yearround wheat is very limited and quite isolated from the main Chinese wheat regions, we attribute little importance to year-round wheat.

West winds prevail during the fall in China, so that the winter-wheat-growing areas of the middle-lower reaches of the Huai and Yangtzi rivers ("HY reaches" =
Area IX in Figure 1) and the middle-lower reaches of Yellow and Huai rivers ("YH reaches" = Area VIII in Figure 1) may receive spores originating from the inoculum sources in the mountains of southern and eastern Gansu Province. We have no evidence showing that the inoculum in the $\mathrm{YH}$ and $\mathrm{HY}$ reaches is related to that formed in Xinjiang Province. Long-term studies on the correlation in disease development between Xinjiang Province and the HY reaches (Area IX in Figure 1) showed that this possibility is very small, probably because of isolation by the desert region in

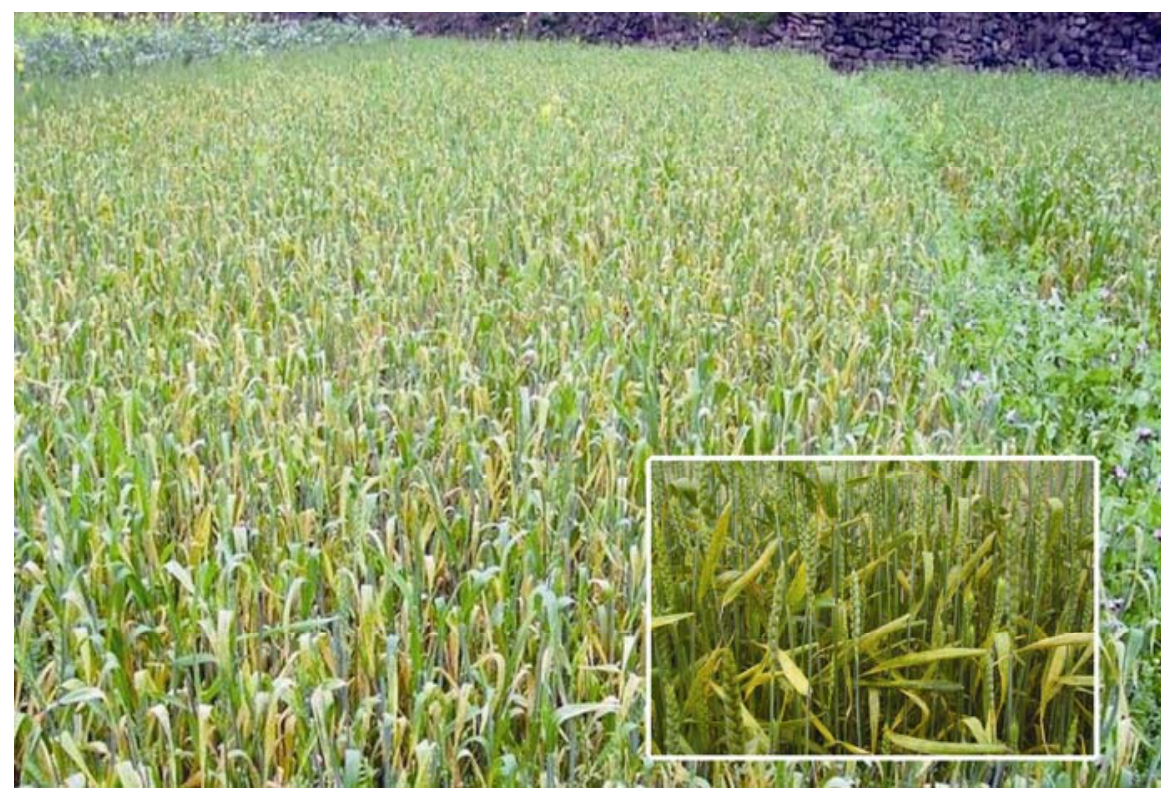

Fig. 3. A field showing an epidemic of wheat stripe rust on adult plants in late season in north-central China.

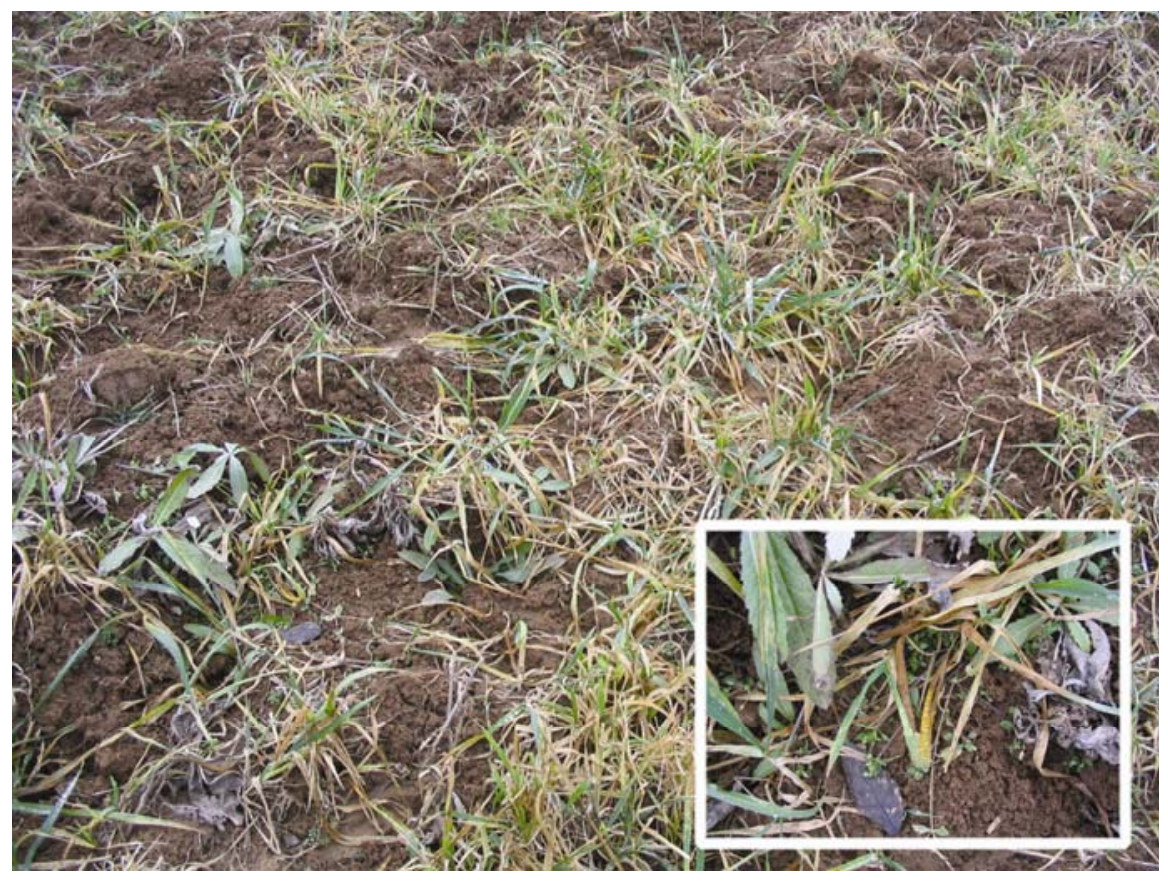

Fig. 4. A field showing that the pathogen Puccinia striiformis can oversummer on the self-sown seedlings from early crops and that the period of epidemics on early crops overlaps with the period of epidemics on late crops. between. Because little information is available on an eventual exchange of inoculum between China and adjacent countries, the present paper focuses on the epidemics in the major wheat-growing regions, excluding that grown in Xinjiang Province.

In the winter-wheat-growing areas of the HY reaches (Area IX in Figure 1), stripe rust can overwinter in infected leaf tissue and disease can even progress slowly during winter. The overwintering inoculum can initiate epidemics in these areas during spring. In the areas of the $\mathrm{YH}$ reaches, however, comparatively lower overwintering rates were observed. In north-central China (i.e., northern areas of Yellow River reaches $=$ Area XI in Figure 1), the rust does not overwinter well due to the low temperature, and hence the amount of early-spring inoculum is often quite low. The pathogen basically cannot overwinter in the northern areas from Shijianzhuang to Dezhou. A huge amount of exogenous inoculum from the HY reaches can invade the more northern area carried by southern winds if the spring outbreak in the south is early and severe. Similarly, spores produced by overwintering sources in the HY and $\mathrm{YH}$ reaches can migrate to the western mountains when eastern winds prevail in spring. These migrations may be of no importance to the year-round life cycle of the fungus, but their effect on race shifts of the pathogen, due to the selection pressure exerted by the gigantic population of host cultivars, cannot be overlooked (24).

In regions where the pathogen can overwinter but not oversummer, initiation of fall epidemics can be caused only by the spores arriving as "exogenous inoculum" from the western mountains. Following some disease development in the fall, the overwintering inoculum can serve as "local" or "endogenous" inoculum, causing spring-time epidemics. However, spring epidemics in these regions may also be caused by inoculum coming from the south, where disease develops earlier. As to the onset of epidemics, the "fall inoculum" usually is exogenous, whereas spring and summer inoculum may be either of local or of exogenous origin. In the first case, the inoculum may consist of the progeny of fall inoculum from the western mountains. In other words, an area may be affected by two different rust populations, the fall one originated in the western mountains and the spring/summer one developing locally or coming from the south. Such twofold invasions of stripe rust illustrate the complexity of interregional epidemiology in China.

The epidemiology group at the China Agricultural University (CAU, formerly Beijing Agricultural University) began its systematic research on wheat stripe rust in the mid-1950s. The first study (16), published in 1962, dealt with the quantitative field-scale analysis of Vanderplank's (11) 
apparent infection rate $(r)$ in relation to precipitation and temperature. Data from individual fields and experimental plots were used to describe the relationship by a multiple regression equation. These data were also used to generate a mathematical model to estimate the distance of disease spread (17). The group did many surveys, including determining the occurrence of different races at different geographical scales, from field to region, to answer questions about region-level epidemics.

\section{Regional Classification of Epidemics}

Many institutions in China, such as the Institute of Plant Protection (CAAS) and the Institutes of Plant Protection of Shaanxi, Gansu, Ningxia, Shanxi, Hebei, and Henan provinces, collaborated to determine the characteristics of regional and interregional stripe rust epidemics in an attempt to classify epidemic regions. This review provides a classification of these epidemics based on the understanding of characteristics of individual regions and the relationship in disease development among regions. In China, all wheat- growing areas within the geographic ranges of 97 to $135^{\circ} \mathrm{E}$ and 22 to $53^{\circ} \mathrm{N}$ are embedded in one epidemic system, while Xinjiang and Xizang (Tibet) belong to other epidemic systems that are far smaller and less important. In terms of disease severity and yield loss, the important epidemic regions are located in north-central China and along the upper and middle reaches of the Yangzi River (Area IX in Figure 1). The eastern and southern Gansu Province and the northwestern Sichuan Province are key regions where stripe rust can complete its year-round life cycle.

Zeng $(20,22)$ proposed the concept of a regional epidemic system according to the regional characteristics of disease development, and attempted to classify the major areas of stripe rust epidemics into 15 different epidemic regions (ER) in China. The kind of region intended is neither administrative nor geographic, but agricultural. The classification is based on unique features of stripe rust epidemics (Table 1). Each ER has its own combination of characteristics, including meteorological characteristics such as maximum temperature in summer, minimum temperature in win- ter, and monthly precipitation in the growing season, and geographic features such as elevation, isotherm and isohyets zones, and mountains. Relevant agricultural features include sowing and harvest dates and wheat growing period with seedling growth in the fall and crop growth rate in the spring. These features determine the development, frequency, and intensity of the disease and the specific inoculum situation of the regions. The classification was made based upon 77 representative geographic locations. Table 1 lists these ERs and their features, and Figure 1 shows the geographic locations where the possible pathways of long-distance disease spread occurs among them. ERs may relate to each other by inoculum exchange. Correlations in disease development between ER and the resulting temporal and spatial patterns of epidemics were analyzed using historical data (14). Table 2 lists abbreviations and symbols used in the text and their corresponding descriptions.

\section{Long-Distance Disease Spread}

Long-distance disease spread exists on different continents. North America can be

Table 1. Fifteen regions classified as epidemic regional systems of wheat stripe rust in China ${ }^{\mathrm{a}}$

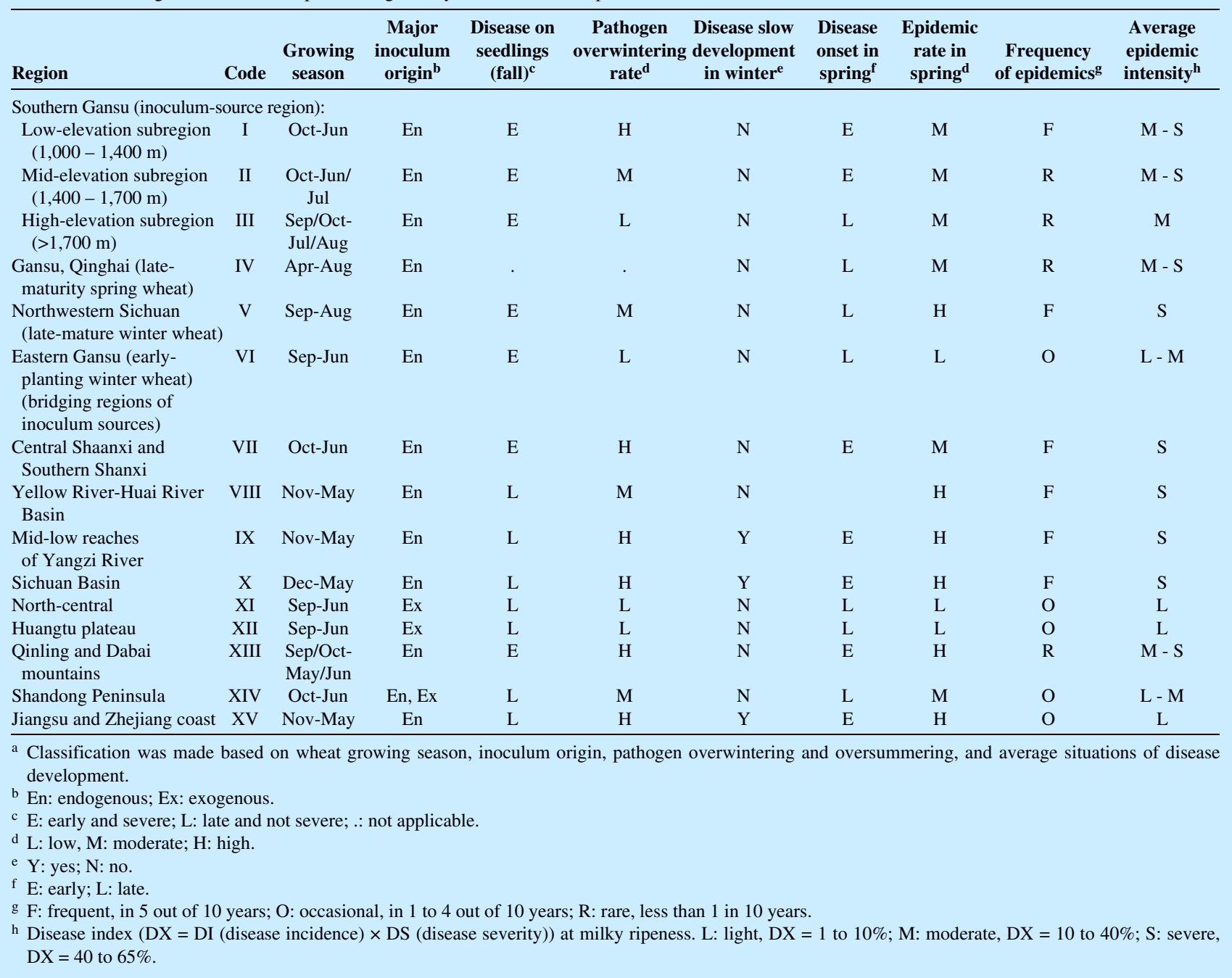


divided into seven stripe rust regions (8) based on geographic, climatic, and cropping characteristics, where long-distance disease spread among these regions was observed. In the northwestern parts of Europe, long-distance dispersal of spores and disease spread exist, covering distances up to $800 \mathrm{~km}$ (15). Recent studies (5) with molecular approaches detecting clonality of genotypes in pathogen populations also demonstrated the disease spread from the UK to Germany and France and then to Denmark. Epidemics of stripe rust in different regions of China vary in frequency and intensity. With respect to stripe rust, the major wheat growing areas covering the valleys of the Hai River, the Yellow River, the Huai River, and the Yangzi River form an independent epidemic system that is geographically isolated by mountains and deserts from Xinjiang and Tibet, where some wheat also is grown (less than $1 \%$ of that in major wheat-growing area) (Fig. 1). We have no evidence whatsoever for regular inoculum exchange between the Chinese plains on the one hand and Xinjiang or Tibet on the other hand, even though inoculum exchange among Xinjiang, Tibet, and the western neighbor countries such as India and Pakistan might exist.

Investigation of long-distance disease spread is essential to understand the origin and pathway of the inoculum arriving at different locations (1). The apparent infection rate $r$ of Vanderplank (11) can be used to make inferences about the possible origin of the inoculum in any specific location. Ideally, the $r$ value should be calculated using a sequence of disease assessments in a field or location where disease stemmed from local inoculum without any interference from exogenous inoculum. In reality, however, an observed $r$ value might be the result of a combination of endogenous and exogenous inoculum. In southeastern China, disease develops early in the spring from endogenous inoculum, whereas in spring-wheat- growing regions, disease can only be due to exogenous inoculum.

A study of $r$ could help to differentiate between the two types of inoculum. The $r$ value derived directly from observed data is called "observed $r$ " $\left(r_{\mathrm{ob}}\right)$, whereas the $r$ estimated indirectly using initial inoculum and weather data is called "calculated $r$ " $\left(r_{\mathrm{cd}}\right)$.

Disease surveys and field observations. Direct assessment of long-distance dispersal of uredospores was not feasible in the 1950s and 1960s. Our major approach was the observation of unique features of disease development in specific regions at different times and the study of relationships between regional epidemics. Features related to regional disease development included characteristics of geography and wheat cultivation methods typical for the various regions. Specific regional features included measurement of disease development on seedlings in the fall in terms of prevalence, incidence, severity, and reaction types. For example, if 100 fields in a county (administrative unit under a province) were investigated and 10 fields showed at least a single diseased leaf, the prevalence in this county was estimated to be $10 \%$. Ten random sampling plots per field showing disease were used. The average of the products of disease incidence (DI, number of diseased leaves/total leaves) and the average disease severity (DS, diseased leaf area/total leaf area) from all these diseased fields were used to calculate the disease index (DX) $(\mathrm{DX}=\mathrm{DI} \times \mathrm{DS})$, which represented the disease situation of this county. The pathogen's regional overwintering rate was determined by averaging the quotients of incidence at the reviving stage in spring and incidence in mid- or late-December of the previous year from representative fields. The $r$ values as well as the final disease indices were used in studying longdistance spread of the disease.

Inference on relationships between different regional epidemics was based on

Table 2. Description of symbols or abbreviations in the text

\begin{tabular}{ll}
\hline $\begin{array}{l}\text { Abbreviation } \\
\text { or symbol }\end{array}$ & Description \\
\hline $\mathrm{D}$ & Distance of disease spread in km \\
$\mathrm{DI}$ & Disease incidence (no. diseased plants/no. total plants) \\
$\mathrm{DS}$ & Disease severity (diseased leaf area/total leave area) \\
$\mathrm{DX}$ & Disease index = DI $\times$ DS \\
$R$ & Regional apparent infection rate \\
$r$ & Vanderplank's apparent infection rate \\
$R_{\mathrm{cd}}$ & Calculated regional apparent infection rate \\
$R_{\mathrm{ob}}$ & Observed regional apparent infection rate \\
$\mathrm{XE}$ & Severely infested fields in hectares $\times$ average incidence $\times$ average severity \\
$\mathrm{PP}$ & Monthly precipitation in mm \\
$\mathrm{RD}$ & Monthly number of rainy days \\
$\mathrm{TE}$ & Monthly average temperature \\
$\mathrm{ER}$ & Epidemic region \\
$\mathrm{HY}$ & Middle-lower reaches of Huai River and Yangtze River (Area IX in Figure 1) \\
YH & Middle-lower reaches of Yellow River and Huai River (Area VIII in Figure 1) \\
\hline
\end{tabular}


Observed and calculated apparent infection rates. One assumption underlying the multiyear surveys was that if $r$ was relatively high during a certain period, the causal inoculum might have contained a considerable amount of exogenous inoculum.

DXs assessed at onset and end of those epidemics, that could be attributed to endogenous inoculum were used to calculate Vanderplank's (11) $r$. The averages of $r$ values from several fields per county were used to calculate a regional value called regional apparent infection rate $(R)$. Weather data were collected from meteorological stations near the sampling plots or survey fields. A regression equation (equation 1) was obtained using multilocation disease and weather data (18):

$$
R=\frac{1.16 * \mathrm{RD}+0.1 * \mathrm{PP}+0.95 * \mathrm{TE}-2.6}{100}
$$

where $\mathrm{RD}=$ monthly rain days $(>0.1$ $\mathrm{mm} /$ day), $\mathrm{PP}=$ monthly precipitation in $\mathrm{mm}$, and TE $=$ monthly average temperature $\left({ }^{\circ} \mathrm{C}\right)(5<\mathrm{TE}<20)$ calculated from daily average temperatures from records at four times per day $(100,700,1300$, and 1900) at 1.5-m height. Equation 1 applies to all regions of China since it is based on the following points: (i) all input data were means derived from 50 to 100 observations in an area of several $\mathrm{km}^{2}$; (ii) all data were from one susceptible cultivar, Bima \#1; and (iii) all data came from fields under uniform cultural and management practices implemented according to the rural management system at that period of time, a system that favored uniform disease investigation methods.

The $R$ values estimated by equation 1 may be viewed as calculated regional apparent infection rates $\left(R_{\mathrm{cd}}\right)$ related to meteorological data, intensity of initial local inoculum, and disease development in a combination of susceptible cultivar and virulent race. Annual variation of $R_{\mathrm{cd}}$ can be studied by using meteorological data from successive years.

Another estimate of $R$, called observed $R\left(R_{\mathrm{ob}}\right)$, can be obtained from the observed disease incidences $x_{1}$ and $x_{2}$ at times $t_{1}$ and $t_{2}$. If the epidemics were initiated by local inoculum only, the values of $R_{\mathrm{ob}}$ and $R_{\mathrm{cd}}$ should be statistically equal. If, however, an epidemic was initiated by exogenous inoculum or by a combination of local and exogenous inoculum, $R_{\mathrm{ob}}$ should exceed $R_{\text {cd. }}$. So, a tentative conclusion on regional inoculum sources can be based on a statistical comparison of $R_{\mathrm{ob}}$ and $R_{\mathrm{cd}}$. Some original data and corresponding statistical analyses were not available due to the political situation in China during the study period.

Estimation of the maximum regional epidemic rate (RER). Equation 1 was used to estimate the maximum possible epidemic rate using extreme conditions of inoculum and weather for a region. For example, for the RD, PP, and TE values of 30,150 , and 20 , respectively, $R_{\text {cd }}$ would be 0.67 . Such extreme weather conditions would be quite exceptional. An extraordinarily severe epidemic of stripe rust occurred in northwestern and north-central
China in 1964. The three weather parameters for April were $\mathrm{RD}=23, \mathrm{PP}=118$, and $\mathrm{TE}=16$ in the Beijing area. The predicted $R_{\mathrm{cd}}$ was 0.51 , whereas the $R_{\mathrm{ob}}$ was 0.44 . The cause of the difference between $R_{\mathrm{cd}}$ and $R_{\mathrm{ob}}$ might be the unpredictable variations in disease observation at different regions. Since such extreme weather conditions are infrequent in China, an $R_{\mathrm{cd}}$ of around 0.50 is a fair estimate of the maximum possible regional epidemic rate $\left(R_{\max }\right)$ of stripe rust in China.

Monitoring interregional spread of the disease. Generally speaking, stripe rust appearing in late fall or early spring is most likely caused by local inoculum or by inoculum from oversummering areas, while the epidemics in mid- and lateseason may be attributed, entirely or in part, to exogenous inoculum coming from areas where the pathogen overwintered and the epidemics occurred early. By comparing $R_{\mathrm{cd}}$ and $R_{\mathrm{ob}}$ values per region, inferences can be made about possible inoculum sources and directions of disease spread. When $R_{\mathrm{ob}}$ in a vast region by far exceeds its $R_{\mathrm{cd}}$, this region is designated as a target region of long-distance spore dispersal.

The multiyear investigations on possible pathways of long-distance disease spread were accumulated (20). An interesting and convincing case occurred in 1960 in the plains of Henan Province, where stripe rust developed very early and severely with an average DX $>2.5 \%$ on 20 April. The total area showing such severe disease was over 0.2 million hectares. However, in Hebei

Table 3. Examples of multiyear observations of disease development in different regions to infer long-distance spread of wheat stripe rust (Puccinia striiformis) in China

\begin{tabular}{|c|c|c|c|c|c|c|c|c|c|c|c|c|}
\hline \multirow[b]{2}{*}{ Year } & \multicolumn{6}{|c|}{ Source region } & \multicolumn{4}{|c|}{ Target region } & \multirow{2}{*}{$\begin{array}{c}\text { Distance } \\
(\mathrm{km}) \text { betw. } \\
\text { two } \\
\text { regions (D) }\end{array}$} & \multirow{2}{*}{$\begin{array}{c}\text { Disease } \\
\text { dilution } \\
(\mathbf{X E} / \mathbf{X})\end{array}$} \\
\hline & Location & Code $^{a}$ & Date & Area $^{\mathbf{b}}$ & $\mathbf{D X}^{\mathbf{c}}$ & $\mathbf{X E}^{\mathbf{d}}$ & Location & Code & Date & $\mathbf{X}^{\mathbf{e}}$ & & \\
\hline 1960 & Jishan/Shanxi & VII & $25 \mathrm{Apr}$ & $10^{4}(667)$ & 0.01 & 100 & Hanyuan & VII & 1 May & 0.0025 & 10 & 40,000 \\
\hline 1960 & $\begin{array}{l}\text { Zhengzhou/ } \\
\text { Henan }\end{array}$ & XI & $30 \mathrm{Apr}$ & $\begin{array}{l}5 \times 10^{6} \\
(333,333)\end{array}$ & 0.025 & 125,000 & $\begin{array}{l}\text { Ci County/ } \\
\text { Hebei }\end{array}$ & XI & 12 May & 0.006 & 180 & $20,800,000$ \\
\hline 1960 & South Shanxi & VII & $30 \mathrm{Apr}$ & $\begin{array}{l}5 \times 10^{5} \\
(33,333)\end{array}$ & 0.08 & 40,000 & Taigu/Shanxi & VII & 15 May & 0.0005 & 300 & $80,000,000$ \\
\hline 1960 & Henan & XI & 5 May & $\begin{array}{l}5 \times 10^{6} \\
(333,333)\end{array}$ & 0.03 & 150,000 & $\begin{array}{l}\text { Northeastern } \\
\text { Hebei }\end{array}$ & XI & 15 May & 0.0005 & 600 & $300,000,000$ \\
\hline 1960 & Hebei & XI & 30 May & $\begin{array}{l}8 \times 10^{6} \\
(533,333)\end{array}$ & 0.02 & 160,000 & Shenyang & $\mathrm{O}$ & 10 Jun & 0.0005 & 720 & $320,000,000$ \\
\hline 1961 & Yongji/Shanxi & VII & $15 \mathrm{Apr}$ & $100(6.7)$ & 0.00014 & 0.014 & Yongji & VII & 1 May & 0.000025 & 0.7 & 560 \\
\hline 1961 & Shuito/Shanxi & VII & 1 May & $20(1.3)$ & 0.0009 & 0.018 & Shuito & VII & 15 May & 0.000035 & 0.9 & 514 \\
\hline 1964 & Northern Hebei & $\mathrm{XI}$ & $30 \mathrm{Apr}$ & $\begin{array}{l}4 \times 10^{7} \\
(2,666,667)\end{array}$ & 0.1 & $4,000,000$ & Shenyang & $\mathrm{O}$ & 15 May & 0.006 & 900 & $660,000,000$ \\
\hline 1975 & $\begin{array}{l}\text { South-central } \\
\text { Hebei }\end{array}$ & XI & $30 \mathrm{Apr}$ & $\begin{array}{l}2 \times 10^{6} \\
(133,333)\end{array}$ & 0.1 & 200,000 & $\begin{array}{l}\text { Northeastern } \\
\text { Hebei }\end{array}$ & XI & 20 May & 0.0025 & 270 & $80,000,000$ \\
\hline 1983 & $\begin{array}{r}\text { Southern Henan/ } \\
\text { Northern Hubei }\end{array}$ & XI & $5 \mathrm{Apr}$ & $\begin{array}{l}2 \times 10^{7} \\
(1,333,333)\end{array}$ & 0.2 & $4,000,000$ & Harbin & $\mathrm{O}$ & 15 May & 0.001 & 1,800 & $4,000,000,000$ \\
\hline
\end{tabular}

a Based on epidemiological regions described in Table 1. O: northeastern China, out of the epidemic regions.

${ }^{\mathrm{b}}$ In Chinese $m u$ (in hectares).

c Disease index $=$ disease incidence $\times$ disease severity.

$\mathrm{d}$ Disease intensity in the source region: $\mathrm{XE}=$ area (in Chinese $m u) \times \mathrm{DX}=$ disease intensity in source region.

${ }^{\mathrm{e}}$ Disease intensity in the target region $\left(\mathrm{DX}_{\mathrm{reg}}\right)$ according to equation $2\left(\mathrm{DX}_{\mathrm{reg}}=\mathrm{XE} / \exp [5.04+2.27 \ln (D+1)]\right.$, where $D$ is the distance $(\mathrm{km})$ between the source region and the target region. The equation is valid when the weather is favorable for infection and susceptible cultivars are extensively grown in the target region. 
Province, north of Henan Province, including $\mathrm{Ci}$ County, Ningjin, Baoding, and Beijing districts, the disease was not found until 1 May, with very few exceptions showing a DX $<0.01 \%$ due to lack of local overwintering inoculum. After early May, the disease was simultaneously observed in the fields in northern and central Hebei Province, where it developed rapidly. $R_{\mathrm{ob}} \geq$ 0.8 , far higher than the $R_{\mathrm{cd}}(<0.3)$ that local weather conditions with local initial inoculum would allow. Obviously, the severe disease in these northern areas was caused by inoculum from the adjacent Henan Province following long-distance dispersal (about $600 \mathrm{~km}$ ), since other provinces showed significantly less severe disease with lower prevalence. The synoptic weather charts supported the inference about Henan and Hebei provinces being the source and target regions, respectively. Beyond May, Hebei Province experienced abnormally high rainfall with southerly winds that promoted disease development. Encouraged by this case, which showed the validity of our approach, many similar instances of regional disease spread were identified from the 1960 s to 1980 s (Table 3).

Quantitative analysis of long-distance spread of disease. Table 3 lists 10 instances of long-distance disease spread from 5 years. Equation 2 summarizes the relationship between disease intensities in target and source areas provided that susceptible cultivars were grown and weather conditions were favorable for infection:

$\mathrm{DX}_{\mathrm{reg}}=\mathrm{XE} / \exp [5.04+2.27 \ln (D+1)]$

where $\mathrm{DX}_{\text {reg }}$ is the average disease index in the target region, $\mathrm{XE}$ is the product of the surface area of severely infested fields in Chinese $m u(1 \mathrm{mu}=0.067 \mathrm{ha}) \times$ average incidence $\times$ average severity, similar to the Disease Mass defined by Zadoks (15), and $D$ is the center-to-center distance in kilometers between the source region and the target region. The equation undoubtedly needs improvement.

Relationship between inoculum quantity and distance of disease spread. Zeng (17) observed that, weather conditions being equal, the radius of expanding disease foci (secondary infection) correlated positively with the disease severity of the initial foci (primary infection). Using data from multiyear surveys, several regression equations were obtained to describe the relationship between disease intensity of the primary infection and distance covered by disease after one latent period in a focus under various precipitation levels (19). The spreading distance was measured as the maximum radius of the focus $(D)$ following one latent period. The initial disease intensity of the focus was determined as the number of sporulating leaves multiplied by their average rust severity. Three weather conditions, described as total pre- cipitation (mm) during the 10 days in which the primary infection was shedding spores, $\geq 20,4$ to 9 , and $\leq 3$, were used in these regression equations (Table 4).

Simulation modeling approach. The regional classification of epidemics, predictions of regional epidemic rate, the quantification of long-distance spread of disease, and parasitic fitness are the building blocks of the simulation model PANCRIN (18,21), developed to study regional epidemics, accounting for race $\times$ cultivar interactions in the various regions. The model was used to estimate the probability of a given level of disease in the various regions, disease intensity in different periods, and race frequencies (25).

Since the late $1990 \mathrm{~s}$, elimination of wheat cropping in the oversummering regions has been discussed in China as a regional disease management strategy. Many questions were raised, such as how to determine the geographic boundaries of this strategy and how to evaluate its effects. PANCRIN was used as a tool to address some of these questions $(23,24)$. Simulation results demonstrated that this strategy of abandonment can significantly reduce the inoculum in some regions. The effect of the strategy on disease control depends on the percentage of wheat fields abandoned. A minimum of $95 \%$ of the wheat fields should be abandoned, since otherwise conditions favorable to disease development could annihilate the effect of abandonment. A clear definition of the geographic boundaries of the oversummering areas is crucial but difficult. Another critical point is that the geographic latitude $\left({ }^{\circ} \mathrm{NL}\right)$ for stripe rust oversummering varies with year.

PANCRIN was applied to study strategies of regional cultivar deployment with a view to reduce the risk of epidemics and to delay the breakdown of resistance. Results (24) indicated that the wheat maturity date in the pathogen's oversummering regions is an important factor in the design of such a strategy. Increasing the number of resistant cultivars and properly organizing the relative hectarages of these cultivars are acceptable strategies for regional disease control. Under the conditions used in this study, the planting area of each resistant cultivar should be less than $15 \%$ of total planting area, and the number of resistant cultivars should surpass six. The planting area of susceptible cultivars should be below $10 \%$. As to race $\times$ cultivar combinations under the given conditions, Zeng (24) concluded that a cultivar(s) with vertical resistance might exhibit a prolonged durability of resistance against the corresponding races if these had a relatively low aggressiveness. This conclusion is fairly consistent with that of Leach et al. (6).

For further applications, PANCRIN can be extended to more regions when new information from regional classification studies becomes available. The model responds to number of cultivars and races, period of the year, number of years, and weather data. For instance, when this model was used to study the overwintering and oversummering of the pathogen, the divisions into epidemic regions could be refined according to estimated oversummering and overwintering rates used as inputs. More cultivars and races can be added as inputs to the model for the study of race dynamics and of deployment of resistant cultivars using available parasitic fitness values. Complementary models to study interregional disease spread were reported by Sun and Zeng (10). Two cases of disease spread were considered, spread from a single source region and spread from various source regions. Eight data sets were used in the single source case, and an exponential regression model was established to estimate DXs in the target regions based on the DX in the source region and the distances between source and target regions. The model was extended to the multiple source case. The spread was simply assumed to occur simultaneously from several regions, and the DXs in the target regions were estimated according to the distance between the target and source regions. After evaluation, experienced plant pathologists concluded that the models produced reasonable results.

\section{Conclusions and Outlook}

Interregional long-distance spread of wheat stripe rust and the pathway in China were inferred by experiments and observations. Since severe interregional epidemics do not occur frequently, the equations used

Table 4. Relationships between precipitation (mm), disease index (DX) of initial focus, and distance of spread of disease $(D)$ after a generation of stripe rust

\begin{tabular}{llcc}
\hline Precipitation $^{\mathbf{a}}$ & Regression equation $^{\mathbf{b}}$ & $\begin{array}{c}\text { Correlation } \\
\text { coefficient }\end{array}$ & \# Observations \\
\hline$\geq 20$ & $\log D=0.4+0.55 \log \mathrm{DX}$ & 0.75 & 7 \\
4 to 19 & $\log D=0.25+0.58 \log \mathrm{DX}$ & 0.92 & 7 \\
$\leq 3$ & $\log D=-0.18+0.56 \log \mathrm{DX}$ & 0.91 & 7 \\
$\begin{array}{l}\text { Combination } \\
\text { of above three }\end{array}$ & $\log D=0.18+0.56 \log \mathrm{DX}$ & 0.95 & 21
\end{tabular}

a Total precipitation $(\mathrm{mm})$ in 10-day period before the generation observed.

b $D$ : distance of disease spread, DX $=\mathrm{DI} \times \mathrm{DS}$. 
to predict the distance of disease spread need to be continuously improved. In the future, molecular markers may help to determine the long-distance pathways $(4,5)$, but visual evidence of long-distance disease spread by means of field observations is imperative to infer pathways of spore dispersal. Thus, grasping the opportunity to study the details in specific cases of regional epidemics is still critical and necessary (13).

Although variation among the considered features is factual, the resulting regional classification of epidemics is subjective, as it depends on the degree of understanding of stripe rust epidemiology. Thus, further validation of this regional classification is needed. The classification may be of great help in understanding the patterns of interregional stripe rust epidemics. The information is useful for regional disease prediction and management, as well as for disease management at the national level, such as interregional deployment of resistant genes (24).

\section{Acknowledgments}

Professor J. C. Zadoks, Department of Phytopathology, Wageningen University and Research Centre, the Netherlands, provided a critical and conscientious review of the previous version of this paper prior to submission. His criticisms, questions, comments, suggestions, and editorial revisions greatly improved the quality of the paper. The authors express their grateful appreciation for his kindness, time, and efforts. The authors also thank Prof. Xiao, Yueyan, and Prof. Ma, Zhanhong, China Agricultural University, for their help in preparation of the photos. The authors also thank Kris Lynn-Patterson, a GIS specialist at University of California, Kearney Agricultural Center, and Tian Luo, a student of the University of California, Berkeley, for their assistance in preparation and modification of the maps.

\section{Literature Cited}

1. Brown, J. K. M., and Hovmøller, M. S. 2002. Aerial dispersal of pathogens on the global and continental scales and its impact on plant disease. Science 297:537-541.

2. Chen, S. M., and Lu, S. Y. 1957. Studies on epidemics of stripe rust on winter wheat in north-central China. Acta Phytopathol. Sin. 3:63-84.

3. Chen, X. M. 2005. Epidemiology and control of stripe rust [Puccinia striiformis f. sp. tritici] on wheat. Can. J. Plant Pathol. 27:314-337.

4. Hamelin, R. C., Lecours, N., and Laflamme, G. 1998. Molecular evidence of distinct introductions of the European race of Gremmeniella abietina into North America. Phytopathology 88:582-588.

5. Hovmøller, M. S., Justesen, A. F., and Brown, J. K. M. 2002. Clonality and long-distance migration of Puccinia striifornis f. sp. tritici in north-west Europe. Plant Pathol. 51:24-32.

6. Leach, J. E., Vera Cruz, C. M., Bai, J., and Leung, H. 2001. Pathogen fitness penalty as a predictor of durability of disease resistance genes. Annu. Rev. Phytopathol. 39:187-224.

7. Li, Z. Q., and Zeng, S. M. 2002. Wheat Rusts in China. China Agriculture Press, Beijing.

8. Line, R. F. 2002. Stripe rust of wheat and barley in North America: A retrospective historical review. Annu. Rev. Phytopathol. 40:75118.

9. O’Brien, L., Brown, J. S., Young, R. M., and Pascoe, I. 1980. Occurrence and distribution of wheat stripe rust in Victoria and susceptibility of commercial wheat cultivars. Aust. Plant Pathol. 9:14.

10. Sun, P., and Zeng, S. M. 1994. Modeling the inter-regional disease spread. Z. Pflanzenkrankh. Pflanzenschutz 101:545-549.

11. Vanderplank, J. E. 1960. Analysis of Epidemics. In: Plant Pathology III. J. G. Horsfall and A. E. Diamond, eds. Academic Press, New York.

12. Viljanen-Rollinson, S. L. H., and Cromey, M. G. 2002. Pathways of entry and spread of rust pathogens: Implications for New Zealand's biosecurity. N.Z. Plant Prot. 55:42-48.

13. Wan, A., Zhao, Z., Chen, X., He, Z., Jin, S., Jia, Q., Yao, G., Yang, J., Wang, B., Li, G., Bi, Y., and Yuan, Z. 2004. Wheat stripe rust epidemic and virulence of Puccinia striiformis $\mathrm{f}$.

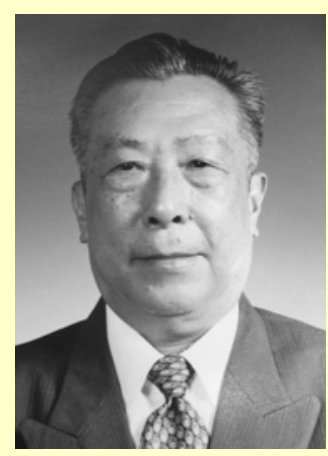

\section{Shi-Mai Zeng}

Professor Zeng is an academician of the Chinese Academy of Engineering and a full professor of China Agricultural University (CAU). He graduated from Peking University and joined the faculty at CAU (formerly Beijing Agricultural University) in 1948. As the pioneer of plant disease epidemiology in China, Prof. Zeng led an epidemiology group at CAU in the 1950s to study the epidemiology of wheat stripe rust and other plant pathosystems. From the late 1950s to late 1960s, Prof. Zeng's group concentrated on features of the pathogen life cycle in China and disease epidemics on a regional scale. Prof. Zeng led huge national research programs in collaboration with many other institutes to study the Puccinia pathway in China. Prof. Zeng published several mathematic models quantitatively describing disease epidemics at field level in as early as 1960s. In the late 1970s, Prof. Zeng's group started systems analysis on disease epidemics with research on both field and computer modeling on epidemics and prediction. His publications and books cover many aspects of epidemiology including basic principles of disease development and management, systems analysis of disease epidemics, applications of horizontal and durable resistance, applications of epidemiological principles in plant breeding for disease resistance, and the concepts of systems engineering of plant protection and macro-phytopathology.
904.

14. Yang, X. B., and Zeng, S. M. 1992. Detecting patterns of wheat stripe rust pandemics in time and space. Phytopathology 82:571-576.

15. Zadoks, J. C. 1961. Yellow rust on wheat, studies in epidemiology and physiologic specialization. Tijdschrift Plantenziekten 67:69256.

16. Zeng, S. M. 1962. On the mathematical analysis of the epiphytotics of wheat stripe rust: I Rate of epidemic. Acta Phytopathol. Sin. 1:3548.

17. Zeng, S. M. 1963. On the mathematical analysis of the epiphytotics of wheat stripe rust: II. Distance of spread. Acta Phytopathol. Sin. 6:141-150.

18. Zeng, S. M. 1981. Preliminary report on the computer simulation of wheat stripe rust in China - A prototype model for spring epi-

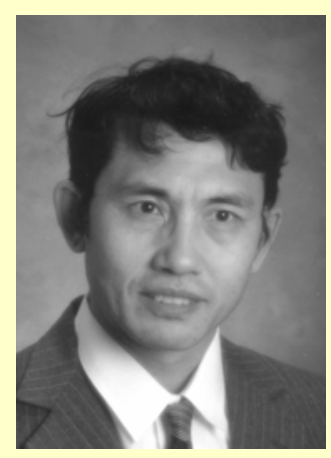

Yong Luo

Dr. Luo received his Ph.D. in 1990 from China Agricultural University (formerly Beijing Agricultural University) under the supervision of Prof. Shi-Mai Zeng and Prof. J. C. Zadoks (Wageningen University, the Netherlands). He became involved in research on wheat stripe rust in his early career, including slow-rusting resistance and simulation modeling of disease epidemics. His research focused on the effects of global climate changes on rice blast epidemics when he worked as a postdoctoral researcher at the International Rice Research Institute (IRRI) from 1992 to 1993 . His research experiences also include biological control of weeds and epidemiology of soybean sudden death syndrome while working at the University of Arkansas and Southern Illinois University as a postdoctoral researcher. Dr. Luo now is an associate project scientist at the University of California-Davis, Kearney Agricultural Center, and an adjunct professor of China Agricultural University. His current research interests are in epidemiology of tree fruit diseases and applications of biotechnology in epidemiological research. 
demic. Acta Agric. Sin. 7:1-2.

19. Zeng, S. M. 1985. Preliminary prediction of pathogen dispersal distance using dispersal gradient model. Acta Phytopathol. Sin. 5:95-102.

20. Zeng, S. M. 1988. Quantitative analysis of long-distance dispersal of urediospores of Puccinia striiformis. Acta Phytopathol. Sin. 18:219-223.

21. Zeng, S. M. 1991. PANCRIN, a prototype model of the pandemic cultivar-race interac- tion of yellow rust of wheat in China. Plant Pathol. 40:287-295.

22. Zeng, S. M. 2000. Epidemics of wheat stripe rust in 2000 and the corresponding regional divisions of epidemics. Z. Q. Li and S. M. Zeng, eds. Wheat Stripe Rust in China. Agricultural Publishing House, Beijing. pp. 207-211.

23. Zeng, S. M. 2003. Simulation studies on oversummering process of wheat stripe rust caused by Puccinia striiformis West. in China. Acta
Phytopathol. Sin. 33:267-278.

24. Zeng, S. M. 2004. Simulation study on cultivar deployment against wheat stripe rust caused by Puccinia striiformis West. in China. Acta Phytopathol. Sin. 34:261-271.

25. Zeng, S. M., and Zhang, M. R. 1990. Simulation experiments on the pandemic dynamic of wheat stripe rust in China by means of a simulation model PANDCRIN. J. Beijing Agric. Univ. 16:(Suppl.)151-160. 